\title{
Unidentified Awareness: Hume's Perceptions of the Self
}

\author{
CHRISTIAN K. CAMPOLO \\ University of Kansas
}

Apparently conflicting statements like the following make it difficult to determine the nature of Hume's concept of self:

It cannot, therefore, be from any of these impressions, or from any other, that the idea of the self is derived; and consequently there is no such idea. 1

According as our idea of ourself is more or less advantageous, we feel either of those opposite affections, and are elated by pride, or dejected with humility. 2

'Tis evident, that the idea, or rather impression of ourselves is always intimately present with us...3

By exploring these claims in their contexts we may be able to assemble a more thoroughgoing account of Hume's concept of self than he presents in any one discussion. Although such a view may provide valuable insights when brought to Hume's troubled treatment of personal identity, that "abstruser science" is not at the heart of this paper. Indeed, in what follows I will argue that Hume rejects a certain notion of personal identity while preserving the kind of self-awareness upon which it claimed to rest.

When Hume discusses personal identity in the first book of the Treatise, he insists that there is no such thing as an "impression or idea of the self." But these same phrases appear later when he explains the workings of human passions-especially those of pride and humility. What are we to make of this apparent inconsistency? The easiest course is one which shares a measure of kinship with other important treatments of Hume--remove the qualification "apparent". Perhaps Hume has contradicted himself. A more conciliatory approach could pursue the suggestion that there is more to learn about the self than we find in the Book I discussions devoted to its rejection. For example, we might become convinced that Hume's discussion of the passions indirectly contributes to

1 David Hume, A Treatise of Human Nature, ed. Nidditch (Oxford: Clarendon Press, 1989), p. 252.

2 lbid., p. 277.

3 lbid., p. 317. 
his account of the self in such a way as to dispel the apparent inconsistency of the passages cited above.

While I believe that Hume's later discussions do reveal additional and important features of his concept of self, I hope to show that both of the above views are implausible. If I am correct, the appearance of inconsistency is an unfortunate result of Hume's use of similar terminology in referring to two very different features of the self. One of these features, a proposed version of personal identity, Hume firmly rejects. The other feature involves a notion of self-awareness which is crucial to his account of human nature. As we will see, Hume explicitly reassigns his terms, withdrawing them from what he rejects while applying them to what he preserves, but the reassignment is not prominent enough to prevent misunderstanding. Where Hume treats differently various topics concerning the self, his reuse of certain phrases creates the appearance of contradiction. If we first consider some weaknesses in the assertion that Hume has genuinely contradicted himself, we can gather the patience to explore my claim in more detail.

Certainly nothing should prevent us from accusing Hume of contradicting himself on trivial or isolated points. But when we see both how varied and how extensive is Hume's concern with the self, we must realize that a genuine contradiction here would deeply disrupt his account of human nature. Preserving such a verdict as a last resort, we ought to heed Hume's warning against considering all statements about the self in the same light.

...we must distinguish betwixt personal identity, as it regards our thought or imagination, and as it regards our passions or the concern we take in ourselves. 4

Although we shall find this distinction far from unproblematical, statements like this one caution us against insisting that every mention of the self be consistent with Hume's initial discussion of personal identity.

Our caution is supported in a less explicit way by Hume's famous recantation of his discussion of personal identity. In the appendix of the Treatise, Hume acknowledges that something is amiss in his treatment of the topic.

...I find myself involved in such a labyrinth, that, I must confess, I neither know how to correct my former opinions, nor how to render them consistent. 5

4 lbid., p. 253. cf., p. 261.

5 Ibid., p. 633. 
Although Hume thus leaves issues of personal identity unresolved, he neither questions nor retracts anything concerning his employment of the concept of self from his later discussion of the passions. We will see that what he does not reject, neither in the early attack on personal identity, nor in the recantation, is precisely that to which he assigns a crucial role in his later discussions of the passions. For the time being, the fact that some Treatise discussions employing the "idea and impression of self" remain immune to his recantation strengthens the view that Hume uses these phrases in what he takes to be consistent ways.

A more general consideration which might lend auxiliary support to the above points involves the way in which Hume derives reinforcement for his account of the understanding from his later account of the passions.

What is principally remarkable in this whole affair is the strong confirmation these phaenomena give to the foregoing system concerning the understanding, and consequently to the present one concerning the passions; since these are analogous to each other. 6

The idea and the impression of self are indispensable components of pride and humility, and they play a role in the functioning of sympathy. If from his account of these passions he garners support for his earlier discussions of the understanding, then he in some measure relies on the idea and impression of the self to bolster the very reasoning which earlier led him to reject the meaningfulness of these same phrases. Either Hume has more than one use for these terms, or the "strong confirmation" that he relishes is actually a broad inconsistency.7

The above reflections show that if we pursue the implications of the accusation of contradiction, we find Hume suffering from a much more extensive and damaging confusion than the accusation initially claims. We should first consider how his different and seemingly conflicting discussions of self might be compatible. Let us proceed to examine each of Hume's treatments of self in order to determine the nature of their relationship.

6 lbid., p. 319. cf., p. 289.

7 Another point, (albeit a highly speculative one), which might suggest that Hume meant to entertain different but compatible notions of self arises from the kind of support which he does not try to garner from his account of the passions. If the idea of the self employed in later sections is the same one which earlier proved an inadequate basis for a theory of personal identity, then why did Hume not try to derive personal identity from pride and humility? For example, would it not, on those assumptions, be possible to isolate the self by focusing more closely on the object of pride? 
In his section on personal identity, Hume briefly characterizes a Cartesian view of personal identity. According to some philosophers, we are always and intimately aware of an identical and simple self. Instead of distracting our attention from this self, sensations and passions only increase the intensity of this awareness. Hume proceeds to attack these "positive assertions" from two directions. First, we simply do not have the described experience of self. Secondly, there could be no perception of self of the kind required for such an experience. We neither have nor could have such a "self."

The relationship between these two objections is open to several interpretations. In opposition to a position taken by Saul Traiger, I do not take these objections to be distinct attacks on distinct philosophical views. ${ }^{8}$ Rather, I read the two attacks as complementary attempts to undermine a single Cartesian theory of personal identity. Hume attacks not two distinct views, but a conclusion as well as the reasoning which leads to it. Concerning the Cartesian self he asks,

...from what impression cou'd this idea be deriv'd? This question 'tis impossible to answer without a manifest contradiction and absurdity...9

By "absurdity" I take Hume to be rejecting a conclusion which is ridiculous in its own right and which has been reached by reasoning which involves "a manifest contradiction".10

The latter objection follows from Hume's empiricist account of the origin of ideas. There could be no such idea of self because no possible impression could give rise to it. If any impression gives rise to the idea of self, that impression must continue invariably the same, thro' the whole course of our lives, since self is suppos'd to exist after that manner. But there is no impression constant and invariable.11

The last sentence in the above quoted passage is not an empirical report-it is the restatement of a conclusion reached earlier. Our impressions are constantly changing. What we conceive of as strict identity is actually a confusion which arises when we perceive an object which remains invariable and uninterrupted over a supposed variation in time. Of course anything that could count as an indication of passing time, such as the ticking of a clock or the lengthening of a shadow, would

8 Saul Traiger, "Hume on Finding an Impression the Self," Hume Studies Vol. XI, No. 1 (April 1985): 47-68.

9 Treatise., p. 251.

10 I am not convinced by Traiger's brief survey of Hume's use of the words "contradiction" and "absurdity" that they are both being used to characterize the same thing.

"Treatise., p. 251. 
invalidate the claim that the impression had remained the same. We would instead have a succession of perceptions related to each other by a strong resemblance. The succession of passions and sensations which Cartesians claim serve to intensify our awareness of self could only really serve to invalidate the self's identity. Further, since the required impression would not cease during one's life, it could not give rise to a complete idea-in this case, one could only think about one's self once the impression of self had ceased, that is, once the person had expired.12

Hume's other objection, that we in fact have no experience of such a self, is easily misconstrued. He says,

For my part, when I enter most intimately into what I call myself, I always stumble on some particular perception or other... I can never catch myself at any time without a perception, and never can observe anything but the perception. When my perceptions are removed for any time, as by sound sleep; so long am I insensible of myself, and may truly be said not to exist. 13

Introspection leads not to a discovery of a self, but of some particular, temporary perception. In the absence of all such perceptions, nothing at all indicates self-existence. Nevertheless, Hume's objection takes the form of an enquiry into what he calls "myself". There is no "simple and continu'd" something waiting to be observed, but Hume says that it is only when his perceptions are remooed that he becomes "insensible of myself". He can never catch himself without a perception, and the perception is all he observes, but these are only further details about what happens when he does "enter intimately" into himself, when he does in fact "catch himself". We can see that Hume is not denying that there is a meaningful use for the word "myself", only that it does not refer to the kind of thing which some philosophers claim it does. Aside from such "metaphysicians", the rest of us...

...are nothing but a bundle or collection of different perceptions, which succeed each other with an inconceivable rapidity, and are in a perpetual flux and movement. 14

12 I take the notion of an ever-present, unchanging impression to be a special case of a singular judgment of immediate perception, and I have here applied to it an idea developed more generally by David Pears in Hume's System. (see pp. 11, 18.)

13 Treatise., p. 252.

14 lbid. 
Somewhat paradoxically, what is perpetual about what I call "myself" is not some unchanging perception, but rather the flux and movement of the perceptions which are mine.

Hume rejects a simple, individuatable, identifiable self, on several grounds, but he at no point rejects what I have been calling self-awareness. Hume is aware of himself, does "enter into" himself, but this awareness is not of some object, but rather of rapidly changing perceptions. With Descartes, Hume can say, "I am; I exist," but he adamantly rejects the reification of that awareness-he refuses to say, "I am a thinking thing." Not only is there no empirical basis for the "absurd" claim of an enduring, unchanging thing which thinks, but the very reasoning which begins from an awareness of perpetual flux and leads to the positing of an enduring entity involves a "manifest contradiction."

So far I have been attempting to show that, despite appearances, Hume has not ruled out meaningful talk about the self-only such talk about a self conceived in a certain way. But showing that meaningful talk about the self is not wholly ruled out is far from showing that contradictory statements about it do not actually conflict. Hume has energetically argued that there are no 'impressions or ideas of the self,' yet he later employs these very phrases. What is required is a demonstration that Hume has reassigned these troublesome phrases to what can still be meaningfully said about the self, and that in his subsequent use of them he wishes only to express these preserved meanings.

I have maintained that Hume allows for self-awareness yet rejects the possibility of basing a theory of personal identity upon this awareness. ${ }^{15}$ If Hume has reassigned phrases like "idea of the self" and found a meaningful way to talk about our "intimate awareness of ourselves" then he must now be referring to the self-awareness he leaves intact. He spends the latter portion of his section on personal identity explaining our irresistable propensity to ascribe identity to what self-awareness shows us, to our "bundle" of successive perceptions.

Our ascription of self-identity is the result of the same mistakes and confusion that induces us to ascribe identity to any other object. The mental process involved in our observation of a succession of related objects is so much like that involved in our (supposed) observation of an invariable and uninterrupted object, that we easily mistake the one state of affairs for the other.

15 For a brief and clear discussion of the relationship between selfawareness and personal identity, see The Character of Mind, by Colin McGinn. 
This resemblance is the cause of the confusion and mistake, and makes us substitute the notion of identity, instead of that of related objects. 16

In the end, our vigilance falters, and we assert that the related but different objects are actually the same. In order to justify and disguise this absurd ascription, we invent some principle which connects the obviously different perceptions. In the same way, when we turn our attention to "ourselves", we "feign the continu'd existence of the perceptions of our senses", and we disguise the misdeed with fictional notions like soul, self, substance, or even more bizarre adhesives.

All ascriptions of identity are accompanied by some fiction, but not all fictions are as undesirable as the metaphysical entities just mentioned. When we ascribe identity to trees, houses, rivers, republics, and other such "compounded and changeable productions" we do not assert that they possess selves or souls, or that their parts are connected by a common substance. The ideas of the various and successive parts of such things provoke our ascription of identity by resembling and causing each other. So too with the self. The identity, which we ascribe to the mind of man, is only a fictitious one, and of a like kind with that which we ascribe to vegetables and animal bodies.17

It is quite acceptable to call that set of constantly (and dramatically) changing perceptions which I frequently encounter in my front garden, "a tree". Further, 1 can talk about perceiving that tree even while admitting that the physical matter out of which it is composed is constantly being replaced. Nor is there any "breach of the propriety of language" when I observe, "our tree is losing many of its leaves in this wind", even though I tacitly ascribe identity to something which is changing before my eyes.

By comparing the kind of identity which we ascribe to the mind to that which we ascribe to things like trees, Hume opens up possibilities for talking about the "idea of the self" without running afoul of his attacks against the Cartesian conception of personal identity. The self is not a simple, durable, invariable entity which is at all times present to our mind's eye-it is never really anything other than a bundle or succession of related perceptions. We are irresistibly inclined to ascribe a sort of fictional unity to our perceptions because they are related in ways which allow them to pass seamlessly before the mind. We need metaphysical entities neither to give rise to, nor to justify our conception of a tree, a river, or ourself. Our awareness of such things allows us to talk and think of them even though they do not come close to meeting the conditions of strict identity. 
This comparison clears the way for Hume's later employment of the impression and idea of the self when he describes the operations of the passions. If we examine some of those later passages we will indeed find that Hume now uses these terms to refer to the continuous flux of perceptions which, as we have seen, allows for self-awareness but which cannot ground personal identity.

In the opening paragraphs of Hume's discussion of pride and humility, we find him explicitly assigning a new meaning to the word "self".

'Tis evident, that pride and humility, tho' directly contrary, have yet the same OBJECT. This object is self, or that succession of related ideas and impressions, of which we have intimate memory and consciousness. ${ }^{18}$

In these few lines Hume allows the self to enjoy a sort of unity while making it clear that this "object" is actually a succession of perceptions. This is the self of self-awareness which remains after the Cartesian self has been dissolved. This is the self of which we may have perceptions. Hume asserts,

Here the view always fixes when we are actuated by either of these passions. According as our idea of ourself is more or less advantageous, we feel either of those opposite affections...19

In order for our idea of self to serve as the object of these passions, Hume requires only that it be available to awareness, not that it satisfy strict identity conditions. Indeed, the possibility that one could have a "more or less advantageous" idea of one's self seems to require that the self not remain unchanged. If, as Hume asserts, "Tis impossible a man can at the same time be both proud and humble...", then it would seem to follow that an invariable self would be forever stuck with one or the other (or neither).

The self we possess is obviously not the Cartesian "thinking thing,". but can it pass the tests that the Cartesian self failed? If Hume is justified in using the word "idea" here, then in accordance with his empiricist principle we should be able to locate the impression from which it arose. Since the idea now under consideration need not remain constant nor invariable, our search is not defeated a priori by the conditions of identity. But if our idea of self involves an awareness of a rapidly flowing stream of impressions to which we fictitiously ascribe unity, do we have here an instance of a single idea which is not derived from a single impression? Perhaps we have-but perhaps this is not a problem. We would simply

18 lbid., p. 277.

$19 \mathrm{lbid}$. 
need to allow that several impressions, even a continuous stream of impressions, could contribute to what is, for all intents and purposes, one idea.20 This is not what Hume does suggest. In fact, he invokes the impression of the self without indicating that he finds any difficulty concerning it.

"Tis evident, that the idea, or rather impression of ourselves is always intimately present with us, and that our consciousness gives us so lively a conception of our own person, that it is not possible to imagine, that any thing can in this particular go beyond it. ${ }^{21}$

Perhaps the impression that Hume mentions here is an impression of reflection, one derived from, rather than giving rise to, the idea of the self. Perhaps Hume, in his re-application of the terms 'idea' and 'impression' is somewhat less inclined to hold to his empiricist doctrine. Whatever the explanation, I must for the time being leave the question open.

Above I have been concerned to show that Hume's statements about the self only apparently contradict each other. Since his treatments of self play such important roles in his explication of human nature, we should resist the urge to accuse him of inconsistency. If I am right, the way to reconcile his almost diametrically opposed statements is to interpret his early treatment of the self as a course of reasoning designed to separate self-awareness from personal identity, to reject the latter, and to preserve the former. It is a difficult interpretation because it is difficult to determine just what it is about the Cartesian conception of self that Hume finds objectionable. Finally, two things force Hume to reject that Cartesian view. First, it conflicts with our experience-we possess no ever-present, simple self. Secondly, though based on a sort of awareness which we do have, it illegitimately posits a metaphysical entity, a strictly identifiable self.

That Cartesian view represents a surrender to the temptation arising from the peculiarly smooth passage of the many different impressions of which we are at each moment aware. Like the Cartesians, we would posit metaphysical entities in order to justify our too-rigid reification of awareness. It is not surprising then, that Hume's later description of the self, which preserves the awareness at the foundation of the Cartesian view, uncannily resembles the views which he seemed to reject so

20 And perhaps such an allowance would also help us to explain the famous "blue-gap" example. We might suggest that the impressions of the two shades of blue bordering on the gap could contribute or be combined into one idea, thus providing an idea of the missing shade. (see pp. 5-6 in the Treatise.)

21 lbid., p. 317. 
enthusiastically. In fact, that primal self-awareness is an essential feature of human nature since it plays a pivotal role in the operation of the passions. We do grant a certain unity to the succession of perceptions which passes before us, but it is a fictitious unity which is neither consciously ascribed nor supportive of a theory of personal identity.

Once Hume has rejected the Cartesian version of personal identity, he is left with its former foundation-self-awareness. In discussing that awareness, he rejuvenates some of the very same phrases which were earlier attached to the rejected personal identity. Hume's failure to justify or even explain his rejuvenation, indeed, his failure to pick new terms, causes an unfortunate appearance of contradiction-he seems to deny and affirm the existence of ideas and impressions of the self. However, a careful look at the relationship between what Hume throws out and what he keeps, at his separation of self-awareness and personal identity, reveals a fairly consistent, naturalistic concept of self. 22

\section{References}

Armstrong, David. A Materialist Theory of the Mind. New York: Humanities Press, 1968.

Bricke, John. Hume's Philosophy of Mind. Princeton: Princeton University Press, 1980.

Hume, David. A Treatise of Human Nature. Ed. P. H. Nidditch. Oxford: Clarendon Press, 1989.

McGinn, Colin. The Character of Mind. Oxford: Oxford University Press, 1982.

Pears, David. Hume's System: An Examination of the First Book of his Treatise. Oxford: Oxford University Press, 1990.

Traiger, Saul. "Hume on Finding an Impression of the Self." Hume Studies, Vol. XI, No. 1 (April 1985): 47-68.

22 I am indebted to Professor John Bricke for his careful and extensive suggestions on a draft of this paper. 